\title{
Effect of Dexketoprofene Trometamol on Post-Endoscopic Retrograde Cholangiopancreatography Pancreatitis
}

\author{
Aziz Ari, Bunyamin Gurbulak, Hasan Okmen, Cihad Tatar, Ufuk Oguz Idiz and Muhammed Zubeyr Ucuncu
}

\begin{abstract}
Objective: To evaluate the efficacy of dexketoprofene trometamol solution following the administration of contrast agent for Endoscopic Retrograde Cholangiopancreatography (ERCP) in decreasing the rate of pancreatitis, in experimental rat model. Study Design: Experimental study.

Place and Duration of Study: Faculty of Medicine, Research and Animal Laboratory of Bezmialem University, Istanbul, Turkey in January 2018.

Methodology: Forty Wistar-Albino ${ }^{\circledR}$ male rats of $250-300 \mathrm{~g}$ were divided into 4 equal groups. Group I underwent cannulation; group II had cannulation with saline; group III had cannulation and contrast agent; group IV had cannulation with contrast agent and dexketoprofene trometamol intra-muscular (IM). Twenty four hours following the procedure, the rats were sacrified and pancreatic tissues were examined histopathologically, with evaluation of blood levels of leukocyte, glucose, SGOT, LDH, amylase, and C-reactive protein (CRP) level. Histopathological grading of acute pancreatitis was performed using haematoxylin and eosin staining.

Results: Mean levels of amylase and leukocyte were found to be significantly higher in groups II, III, IV when compared to group I $(p=0.001)$. CRP level was found to be highest in group III $(p=0.001)$. Histopathological grade of pancreatitis was found to be significantly higher in groups II, III, IV than group I ( $\mathrm{p}: 0.001,0.001,0.028$, and 0.001 , respectively). Scores of edema, acinar necrosis, inflammation and perivascular infiltration of group III were higher than in group IV ( $p=0.001)$.

Conclusion: Intra-muscular administration of dexketoprofen trometamol during ERCP procedure may be beneficial in decreasing the rate of post-ERCP pancreatitis, as shown by histopathological and laboratory profile.
\end{abstract}

Key Words: Endoscopic retrograde cholangiopancreatography (ERCP), Pancreatitis, Dexketoprofen trometamol, Contrast-induced pancreatitis.

\section{INTRODUCTION}

Acute pancreatitis is inflammation of the pancreas with edema, necrosis and hemorrhage. Gallstones and alcohol are the most important non-iatrogenic etiologic agents. ${ }^{1}$

Post-Endoscopic Retrograde Cholangiopancreatography (ERCP) pancreatitis is the most important cause of iatrogenic pancreatitis. Post-ERCP pancreatitis is a serious complication and etiology is multifactorial. ${ }^{2}$

The incidence of post-ERCP pancreatitis is reported to be between $2-10 \%{ }^{3}$ The clinical progress is mild in $85-90 \%$ of the patients, and necrotising pancreatitis with multiorgan failure is encountered in $10-15 \%$ of the patients. 4,5 Although the underlying mechanism of pancreatitis is not fully understood, the activation of mechanical, hydrostatic, chemical and allergic reactions, proteolytic enzymes and inflammatory pathways are the most important causes of pancreatitis. ${ }^{3,6}$

In ERCP procedure, contrast agent is administered directly into common bile duct (CBD) and Wirsung. Contrast

Department of General Surgery, Istanbul Training and

Research Hospital, Fatih 34098, Istanbul, Turkey

Correspondence: Dr. Bunyamin Gurbulak, Department of

General Surgery, Istanbul Training and Research Hospital,

Fatih 34098, Istanbul, Turkey

E-mail: bgurbulak@gmail.com

Received: September 06, 2018; Accepted: February 01, 2019 agent supposedly causes damage to the acinar cells on direct contact. 4,6

Although various pharmacological medications and technical variations are suggested in minimising the rate of post-ERCP pancreatitis, studies evaluating the antiinflammatory effect of the dexketoprofen trometamol are very limited.7 Dexketoprofen trometamol S - (+) - 2(3-benzoylphenyl) propionic acid tromethamine salt is an analgesic, anti-inflammatory and anti-pyretic drug for the nonsteroidal anti-inflammatory drug group..$^{8,9}$ The mechanism of action of non-steroidal anti-inflammatory agents are related to the reduction of prostaglandin synthesis by the inhibition of the cyclooxygenase pathway. In addition, the inhibition of prostaglandin synthesis also affects other inflammatory mediators, such as kinin, leading to an indirect effect in addition to direct effect. Dexketoprofen inhibits prostaglandin synthesis centrally and peripherally.8,10

In this study, the aim was to evaluate the efficiency of the dexketoprofen trometamol administration on decreasing the toxic damage of contrast agent on pancreatic tissue, leading to pancreatitis, in an experimental rat model.

\section{METHODOLOGY}

This experimental study was conducted at Faculty of Medicine, Research and Animal Laboratory of Bezmialem University, Istanbul, Turkey in January 2018. The Animal 
Research Ethics Committee's approval was obtained from Faculty of Medicine, Bezmialem University, Istanbul, Turkey. Following the approval, the research was conducted at the same University laboratory. Forty Wistar-Albino ${ }^{\circledR}$ male rats of $250-300 \mathrm{~g}$ were seperated into 4 randomised groups, with 10 rats in each group. All the experimental protocols were carried out in accordance with the Guide for the Care and Use of Laboratory Animals, Eighth edition (2011).

All animals were housed at standard laboratory conditions with 12-hour light and dark cycle and food and water ad libitum before and after surgery. After the experimental procedure, the animals were individually placed in cages and kept at room temperature $\left(22^{\circ} \mathrm{C}\right)$. All surgical procedures were performed under sterile condition.

At the begining of the experimental procedure, all rats were weighed, which was recorded. Rats were anaesthetised with intra-muscular injections of ketamine hydrochloride $(50 \mathrm{mg} / \mathrm{kg})$ and Xylazine $(10 \mathrm{mg} / \mathrm{kg})$.

In this experimental model, bile duct was cannulated transduodenally, and following the clamping of the hepatic duct with a bulldog clamp, saline solution and contrast agent were administered at $30 \mathrm{mmHg}$ pressure. ${ }^{11}$ With this procedure, an ERCP procedure in obstructive cases that led to retrograde flow of bile to the pancreatic duct, such as stasis due to choledochal stones, edema and tumors of pancreatic head was simulated (Figure 1). A sphygmomanometer cuff of a pediatric blood pressure device was prepared to provide $50 \%$ diluted iodinated contrast agent $(300 \mathrm{mgl} / \mathrm{ml})$ under $30 \mathrm{mmHg}$ pressure. For group IV, dexketoprofen trometamol was administered via intra-muscular route for anti-inflamatory effect.

Forty Wistar-Albino ${ }^{\circledR}$ rats were assigned in four groups. The rats were shaved and then prepared with povidoneiodine. A midline $(5 \mathrm{~cm})$ laparotomy was performed. Then, the abdominal organs were explored. In all groups, the common biliopancreatic duct cannulation was performed by transduodenal with $24 \mathrm{G}$ catheter.

In group I (cannulation group, $\mathrm{n}=10$ ) after cannulation, the abdomen was closed without performing any other procedure.

In group II (Isotonic group, $\mathrm{n}=10$ ), the hepatic duct was clamped following the cannulation with a small bulldog clamp and $0.5 \mathrm{ml}$ isotonic $\mathrm{NaCl}$ (saline) was injected at $30 \mathrm{mmHg}$ pressure. In group III (Contrast group, $\mathrm{n}=10$ ), the hepatic duct was clamped with a small bulldog clamp following the cannulation and $0.5 \mathrm{ml} 50 \%$ diluted contrast agent was injected at $30 \mathrm{mmHg}$ pressure. In group IV (Contrast plus dexketoprofen trometamol group, $n=10$ ), the hepatic duct was clamped with a small bulldog clamp following the cannulation and $0.5 \mathrm{ml} 50 \%$ diluted contrast agent was injected at $30 \mathrm{mmHg}$ pressure. After a slight tension on the foot of the left leg to be injected, the muscle mass located on the dorsal back of the thigh, thigh area midway between the back of the knee and the base of the tail was palpated and $0.25 \mathrm{ml}$ dexketoprofen tremetamol solution was injected. The abdomen was closed with 3-0 silk suture in all the groups.

Twenty-four hours later, after the procedure, all rats were re-anesthetised. Following laparotomy, blood samples were collected by intracardially for biochemical analysis, then the rats were sacrificed by cervical dislocation. For histopathological examinations, the duodenum and whole pancreas tissue were harvested. Blood samples were taken for counting the blood levels of leukocyte, platelet, amylase, glucose, C-reactive protein (CRP), lactate dehydrogenase (LDH), aspartate aminotransferase (AST-SGOT). Specimens were routinely processed and embedded in paraffin wax. Pancreas tissue sections of $5 \mu \mathrm{m}$ thickness were stained with hematoxylin and eosin. Schmidt's method with regard to edema, acinar necrosis, hemorrhage, fat necrosis, inflammation and perivascular infiltration scores was used for presence and grade of acute pancreatitis. ${ }^{8}$

In the descriptive statistics of the data, median lowest, highest, frequency and ratio values were used. The distribution of the variables was measured with the Kolmogorov-Simirnov test. For group analyses, KruskallWallis test was used and intergroup analyses were performed with Mann-Whitney U-test. SPSS 22.0 programme was used in the analysis.

\section{RESULTS}

Neither complication or nor mortality was encountered during the experimental procedure. Histopathological examination of specimens revealed acute pancreatitis in all the groups. A homogeneous distribution was determined between the groups in medians of body weight $(p=0.407)$. There was statistically a significant difference between the groups regarding glucose, CRP, $\mathrm{LDH}$, amylase, and SGOT levels, and leukocyte and platelet counts $(p<0.001$, Table I).

On subgroup analysis of biochemical parameters of pancreatitis criteria, it was observed that all values were high, especially in the contrast group, and all values were decreased statistically, significant in dexketoprofen trometamol (IM) group (Table II).

Leukocyte count, SGOT, glucose, LDH, amylase values of group I were statistically lower than group II and III (all $p=0.001$ ). Platelet count, CRP, LDH and SGOT values of group I were statistically higher than group IV (all $p=0.001$ ). Amylase value in group IV was statistically higher than group I $(p=0.041)$. 
Table I: Biochemical analysis of the groups

\begin{tabular}{|c|c|c|c|c|c|}
\hline & $\begin{array}{c}\text { Group I } \\
\text { Median (Min-Max) }\end{array}$ & $\begin{array}{c}\text { Group II } \\
\text { Median (Min-Max) }\end{array}$ & $\begin{array}{c}\text { Group III } \\
\text { Median (Min-Max) }\end{array}$ & $\begin{array}{c}\text { Group IV } \\
\text { Median (Min-Max) }\end{array}$ & $\mathrm{p}$ \\
\hline Weight & $422.5(396-488)$ & $424.5(367-463)$ & $390.5(345-485)$ & $427.0(364-544)$ & 0.407 \\
\hline Leukocyte & $8.1(4.56-11.26)$ & $12.3(6.91-16.87)$ & $13.6(9.06-25.22)$ & $9.27(4.8-11.79)$ & $<0.001$ \\
\hline Glukose & $111.5(82-252)$ & 134 (118-212) & 206 (134-263) & $123(80-163)$ & $<0.001$ \\
\hline Platelet & $765000(685000-991000)$ & $789000(650000-994000)$ & $778000(48000-936000)$ & $611000(538000-756000)$ & $<0.001$ \\
\hline CRP & $0.21(0.12-0.99)$ & $0.19(0.11-0.23)$ & $0.18(0.11-0.99)$ & $0.01(0.01-0.02)$ & $<0.001$ \\
\hline $\mathrm{LDH}$ & $672.5(265-1514)$ & $949.5(685-2203)$ & $1946.5(890-2242)$ & $382.5(346-691)$ & $<0.001$ \\
\hline Amylase & $2613(912-5366)$ & 3851 (2507-6357) & 6609 (3569-8563) & $4056(1745-8510)$ & $<0.001$ \\
\hline AST & $533(256-635)$ & $711(581-1028)$ & 965 (703-1363) & $276(210-365)$ & $<0.001$ \\
\hline
\end{tabular}

Kruskal-Wallis. AST: Aspartate Aminotransferase. LDH: Lactate dehydrogenase. CRP: C-reactive protein.

Table II: Histopathological examination of the groups.

\begin{tabular}{|c|c|c|c|c|c|}
\hline & $\begin{array}{c}\text { Group I } \\
\text { Median (Min-Max) }\end{array}$ & $\begin{array}{c}\text { Group II } \\
\text { Median (Min-Max) }\end{array}$ & $\begin{array}{c}\text { Group III } \\
\text { Median (Min-Max) }\end{array}$ & $\begin{array}{c}\text { Group IV } \\
\text { Median (Min-Max) }\end{array}$ & $\mathrm{p}$ \\
\hline Edema & $2(1-2.5)$ & $2.5(1.5-3.5)$ & $3(2.5-3.5)$ & $2.5(2.5-3)$ & $<0.001$ \\
\hline Acinar necrosis & $1(0-2)$ & $2.5(1-3.5)$ & $3.25(1-4)$ & $2(0.5-3.5)$ & $<0.001$ \\
\hline Hemorrhage and fat necrosis & $1(0.5-2.5)$ & $1(0-2)$ & $2.25(0.5-3)$ & $1(1-2.5)$ & 0.028 \\
\hline Inflammation and perivascular infiltration & $0.75(0.5-3.5)$ & $3.25(1-3.5)$ & $3.75(2-4)$ & $2(2-4)$ & $<0.001$ \\
\hline
\end{tabular}

KW: Kruskal-Wallis

Glucose, LDH, amylase and SGOT values of group II were statistically significantly lower than group III $(p=0.003,0.001,0.001$, and 0.001 , respectively). Leucocyte and platelet count, glucose, CRP, LDH, SGOT values of group II were statistically higher than group IV ( $p=0.006,0.001,0.023,0.001,0.001$, and 0.001 , respectively).

The mean values of leukocyte and platelet count, glucose, CRP, LDH, and SGOT in group III were statistically higher than group IV $(p=0.002,0.001,0.001$, 0.001 , and 0.001 , respectively).

Serum levels of SGOT, CRP, LDH and platelet count were significantly lower in group IV when compared to other groups $(p=0.004,0.001,0.001-0.001,0.001$, $0.001-0.019,0.001,0.001-0.001,0.001,0.001$ for groups 1, 2, 3 and 4, respectively).

Histopathological assessment of the pancreatic gland was consistent with acute pancreatitis showing interstitial edema, inflammation and perivascular infiltration, acinar necrosis, hemorrhage and fat necrosis in all experimental groups (Figure $2 a-d$ ).

A statistically significant difference was found in the pathological evaluations of the groups. In group II, acinar necrosis, inflammation and perivascular infiltration scores were significantly higher than group I (all $p=0.002$ ).

All of the damage scores were significantly higher in group III, when compared to group I and IV $(p=0.001$, $0.001,0.035,0.001-0.004,0.011,0.143$, and 0.035 , respectively). In group III, scores of edema, acinar necrosis, hemorrhage and fat necrosis were significantly higher than group II ( $p=0.004,0.035,0.025$, and 0.061 , respectively). In group IV, edema, inflammation and perivascular infiltration scores were found to be significantly higher than group I $(p=0.035,0.001$, Figure 3$)$.

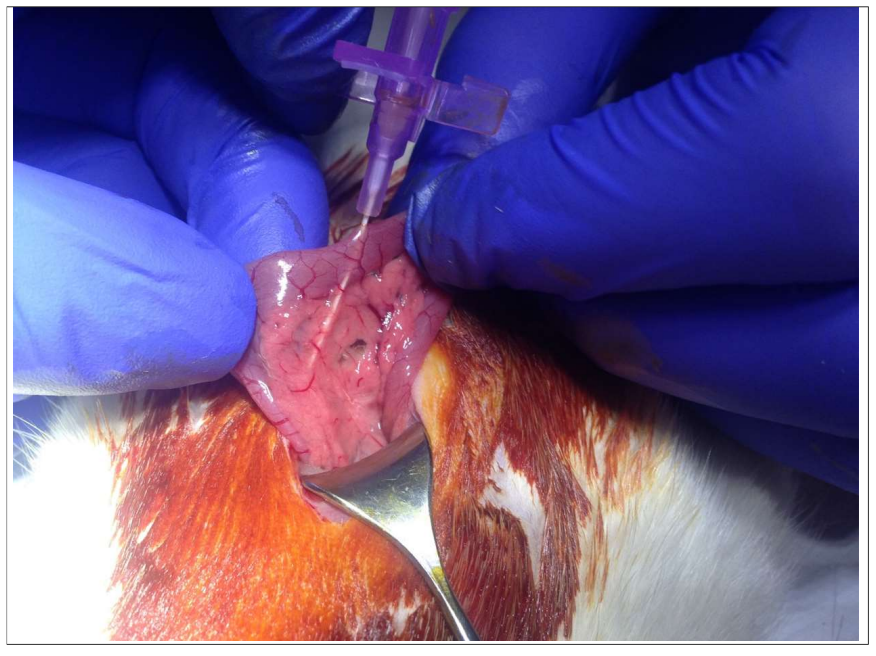

Figure 1: Transduodenal cannulation of common pancreaticobiliary duct.

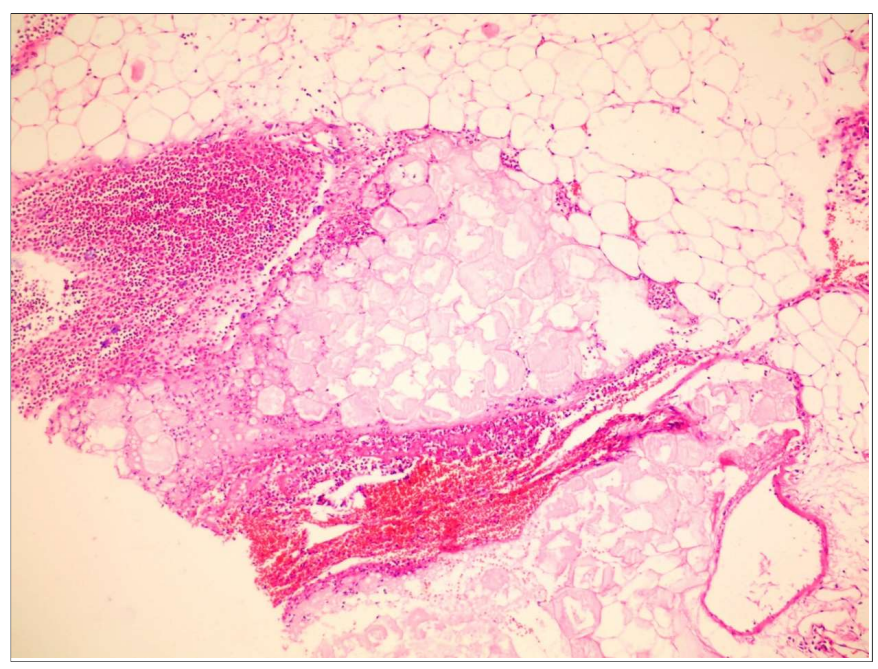

Figure 2a: Hematoxylin-eosin (H-E) staining (400X). Fat necrosis and severe inflammation (H \& E X400). 


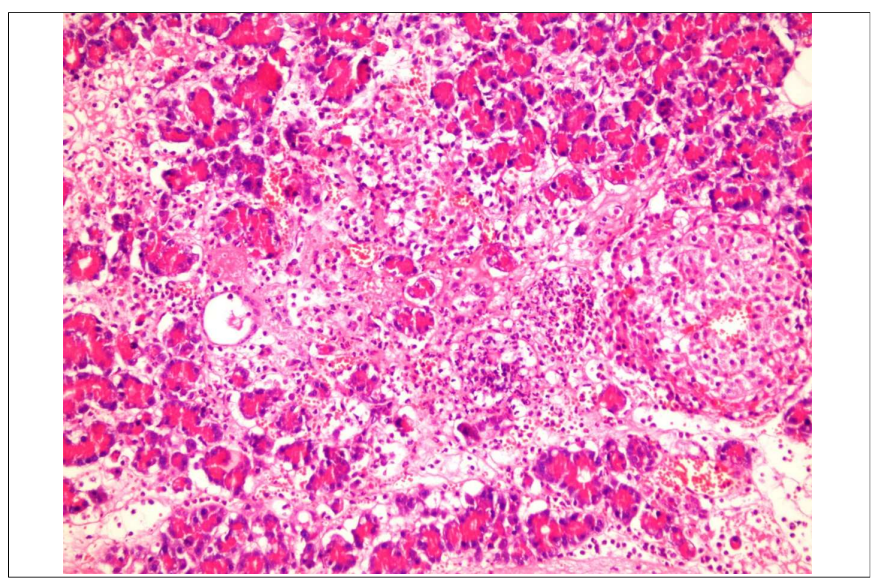

Figure 2b: Hematoxylin-eosin (H-E) staining (400X). Moderate inflammation and edema at the intercellular spaces (H\&E X400)

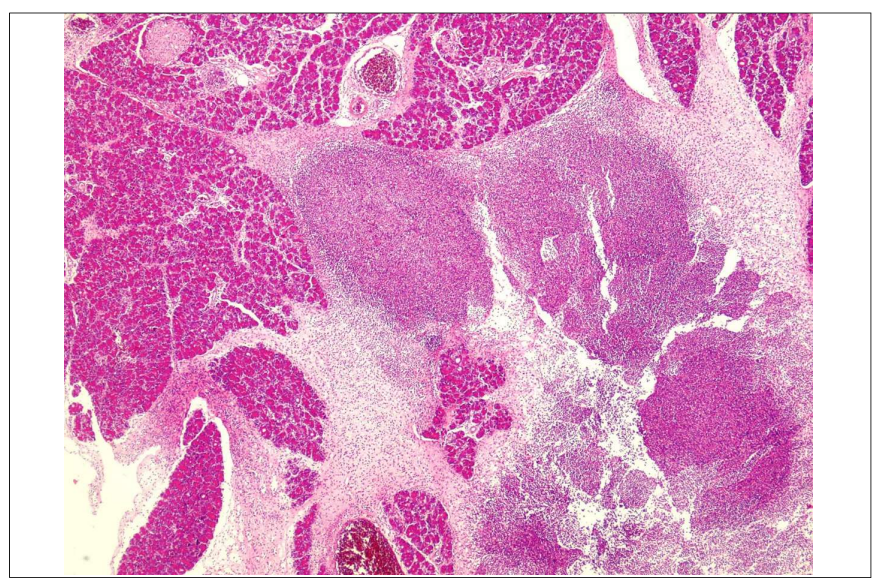

Figure 2c: Hematoxylin-eosin (H-E) staining (400X). Severe inflammation between acinar areas (H \& E X400)

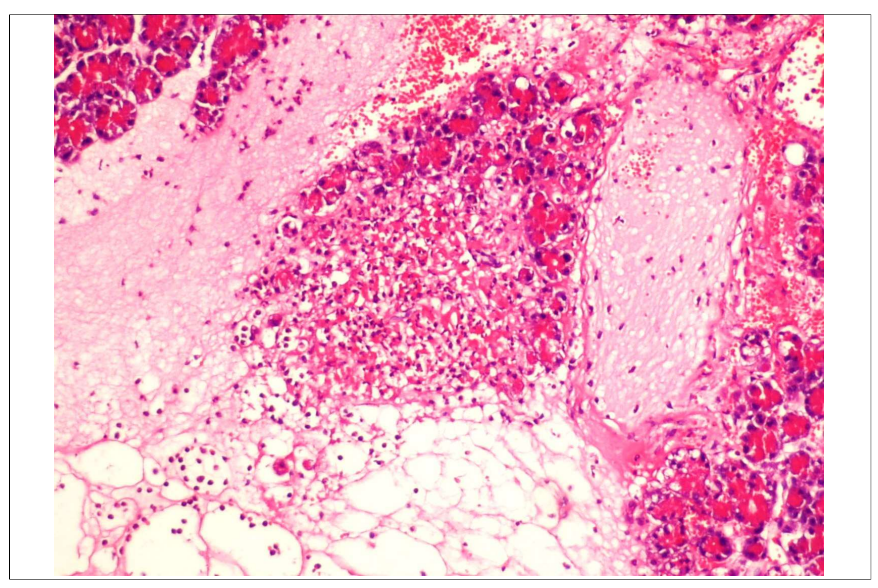

Figure 2d: Hematoxylin-eosin (H-E) staining (400X). Severe acinar necrosis is apparent $(H \& E X 400)$.

\section{DISCUSSION}

Acute pancreatitis is occurred due to calculi of the gallbladder and alcohol abuse, and it is a multifactorial process. Which mechanism triggers pancreatitis has not yet elucidated. It has been also reported that there may be seen life threatening attacks following ERCP, with a rate of $0-5 \% .^{3}$

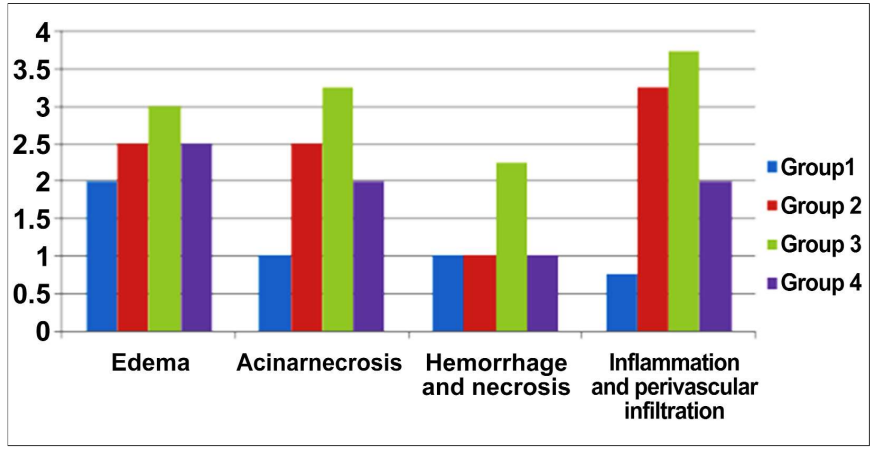

Figure 3: Comparison of the Histopathological injury scores of the groups.

Acute pancreatitis starting with acinar cell damage and secretion of inflammatory mediators caused by a cascade of reactions that leads to clinical presantation may range from asymptomatic disease or a lifethreatening extra pancreatic situation such as systemic inflammatory response syndrome (SIRS) or multiple organ dysfunction syndrome (MODS).12,13

Following acinar cell damage, amylase and lipase release into the systemic circulation in the early stage of pancreatitis. Pancreatic amylase and lipase secretion and elevated levels are the most important predictors of pancreatitis. It increases in serum begin in 2-12 hours and reaches its peak value between 12-72 hours. In uncomplicated cases, the levels come back to normal range in a few days' duration. ${ }^{14}$

A number of anti-inflammatory drugs such as NSAID, steroids, anti-metabolites, antiproteases, antioxidants, heparin, risperidone have been studied to block the inflammatory cascade for preventing post-ERCP pancreatitis. ${ }^{15}$ Indometazine and diclofenac administered rectally are the most effective NSAID on pancreatitis. ${ }^{16-18}$ The mechanism of post-ERCP pancreatitis is multifactorial. The procedure related risk factors of postERCP pancreatitis include difficult and multiple cannulation of papilla and/or pancreatic sphincter, hydrostatic, chemical and/or allergic damage caused injection of contrast agent, pre-cut sphincterotomy and perforation caused by the thermal effect of electrosurgical unit on bile duct or ampulla and unexperienced endoscopist. 3,6,19

The contrast medium is given directly into common biliarypancreatic duct during the ERCP. Although it has been reported in the literature that contrast agents have direct toxic effect on ductal, epithelial and acinar cells. ${ }^{20,21}$ The occurrence of post-ERCP pancreatitis independent from the osmolarity of the contrast agent. 4,22

In this experimental study, efficacy of dexketoprofene trometamol was evaluated, after the administration of contrast agent on post-ERCP panceratitis. In group III, damage scores, biochemical markers and leukocyte count were found to be considerably high. The similar 
damage scores, biochemical findings and leukocyte count in groups II and IV, may be an indication of the advantageous effect of dexketoprofene trometamol in decreasing pancreatic damage.

CRP, which is used to assess the severity of acute pancreatitis, with scoring systems such as Ranson and Apache, is an acute phase reactant.23 In group III, amylase and CRP levels were found to be significantly higher than other groups. Similarly, amylase levels were significantly lower in groups II and IV, than group III. In group IV other prognostic factors such as leukocyte, AST and LDH were lower than group I, II, III.

Biochemical and histopathological pancreatic damage parameters were in correlation with pancreatitis, and found to be highest in group III, similar in groups II and IV. With those results, it was found that dexketoprofene trometamol may be effective in decreasing the destructive results of the chemical effect of contrast agent.

\section{CONCLUSION}

Dexketoprofen trometamol was found to be useful for controlling the post-ERCP pancreatitis. There is a need for randomised controlled trials on large groups of patients.

\section{REFERENCES}

1. Senninger N, Moody FG, Coelho JC, Van Buren DH. The role of biliary obstruction in the pathogenesis of acute pancreatitis in the opossum. Surgery 1986; 99:688-93.

2. Cheon YK, Cho KB, Watkins JL, McHenry L, Fogel EL, Sherman $S$, et al. Frequency and severity of post-ERCP pancreatitis correlated with extent of pancreatic ductal opacification. Gastrointest Endosc 2007; 65:385-93.

3. Freeman ML, Guda NM. Prevention of post-ERCP pancreatitis: A comprehensive review. Gastrointest Endosc 2004; 59:845-64.

4. Kivisaari L. Contrast absorption and pancreatic inflammation following experimental ERCP. Invest Radiol 1979 14:493-7.

5. Borislow D. The etiology of post-ERCP pancreatitis. Gastrointest Endosc 1989; 35:189-90.

6. Cheng CL, Sherman S, Watkins JL, Barnett J, Freeman M, Geenen J, et al. Risk factors for post-ERCP pancreatitis: A prospective multicenter study. Am J Gastroenterol 2006; 101:139-47.

7. Barbanoj MJ, Antonijoan RM, Gich I. Clinical pharmacokinetics of dexketoprofen. Clin Pharmacokinet 2001; 40:245-62.

8. Morgaz J, Navarrete R, Muñoz-Rascón P, Domínguez JM, Fernández-Sarmiento JA, Gómez-Villamandos RJ, et al. Postoperative analgesic effects of dexketoprofen, burenorphine and tramadol in dogs undergoing ovariohysterectomy. Res Vet Sci 2013; 95:278-82.

9. Piparot P, Dupuis J, Grisneaux E, Cuvelliez S, Plante J, Beauregard G, et al. Comparison of ketoprofen, oxymorphone hydrochloride, and butorphanol in the treatment of postoperative pain in dogs. J Am Vet Med Assoc 1997; 211:438-44.

10. Streppa HK, Jones CJ, Budsberg SC. Cyclooxygenase selectivity of nonsteroidal anti-inflammatory drugs in canine blood. Am J Vet Res 2002; 63:91-4.

11. Haciahmetoglu T, Ertekin C, Dolay K, Yanar F, Yanar H, Kapran Y. The effects of contrast agent and intraductal pressure changes on the development of pancreatitis in an ERCP model in rats. Langenbecks Arch Surg 2008; 393:367-72.

12. Dumonceau JM, Andriulli A, Elmunzer BJ, Mariani A, Meister T, Deviere J, et al. Prophylaxis of post-ERCP pancreatitis: European society of gastrointestinal endoscopy (ESGE) guideline - updated June 2014. Endoscopy 2014; 46:799-815.

13. Kochar B, Akshintala VS, Afghani E, Elmunzer BJ, Kim KJ, Lennon AM, et al. Incidence, severity, and mortality of postERCP pancreatitis: A systematic review by using randomized, controlled trials. Gastroint Endosc 2015; 81:143-9.e9.

14. Yeo CJ, Cameron JL. The pancreas. In: Sabiston DC (Ed) Sabiston textbook of surgery, ed. $16^{\text {th }}$. Saunders, Philedelphia; 2001: pp.1116-25.

15. Mäkelä A, Kuusi T, Schröder T. Inhibition of serum phospholipase-A2 in acute pancreatitis by pharmacological agents in vitro. Scand J Clin Lab Invest 1997; 57:401-7.

16. Sethi S, Sethi N, Wadhwa V, Garud S, Brown A. A metaanalysis on the role of rectal diclofenac and indomethacin in the prevention of post-endoscopic retrograde cholangiopancreatography pancreatitis. Pancreas 2014; 43:190-7.

17. Puig I, Calvet X, Baylina M, Isava Á, Sort P, Llaó J, et al. How and when should NSAIDs be used for preventing post-ERCP pancreatitis? A systematic review and meta-analysis. PLoS One 2014; 9:e92922.

18. Elmunzer BJ, Waljee AK, Elta GH, Taylor JR, Fehmi SM, Higgins PD. A meta-analysis of rectal NSAIDs in the prevention of post-ERCP pancreatitis. Gut 2008; 57:1262-7.

19. Rabenstein T, Schneider HT, Bulling D, Nicklas M, Katalinic A, Hahn EG, et al. Analysis of the risk factors associated with endoscopic sphincterotomy techniques: Preliminary results of a prospective study, with emphasis on the reduced risk of acute pancreatitis with lowdose anticoagulation treatment. Endoscopy 2000; 32:10-9.

20. Sherman S, Lehman GA. ERCP- and endoscopic sphincterotomy-induced pancreatitis. Pancreas 1991; 6:350-67.

21. Pezzilli R, Romboli E, Campana D, Corinaldesi R. Mechanisms involved in the onset of post-ERCP pancreatitis. JOP 2002; 3:162-8.

22. George S, Kulkarni AA, Stevens G, Forsmark CE, Draganov P. Role of osmolality of contrast media in the development of post-ERCP pancreatitis: A metanalysis. Dig Dis Sci 2004; 49: 503-8.

23. Riché FC, Cholley BP, Laisné MJ, Vicaut E, Panis YH, Lajeunie EJ, et al. Inflammatory cytokines, C-reactive protein, and procalcitonin as early predictors of necrosis infection in acute necrotizing pancreatitis. Surgery 2003; 133:257-62. 